\title{
PANCRACIOS, QUINQUERCIOS, ABECEDARIO..., Y OTROS JUEGOS PASTORILES
}

Cuando se habla de los libros de pastores y se intenta establecer el perfil de sus protagonistas, una de las características que más llama la atención es su ociosidad. La soledad de este oficio se ha prestado desde antiguo a la conversión del pastor en personaje literario. En el caso concreto de la novela pastoril, los Siralvos, Lerianos o Laurencios que se pasean por estas particulares Arcadias sustituyen, las más de las veces, el cuidado del ganado por el lamento amoroso, y es que la literatura les brinda un entorno adecuado para dedicarse a sentir y a hablar del amor. La sombra de un árbol y la fresca orilla de un río dan vida a unos campos convertidos en testigos de su malestar; pero, además de cantar y de llorar, estos personajes tan acartonados se entregan a una serie de actividades de cariz lúdico, vinculadas a sus circunstancias amorosas o ajenas a éstas. El motivo desencadenante suele ser una fiesta -casi siempre, unos desposorios o, como sucede en el Siglo de Oro en las selvas de Erifile, unas honras fúnebres. Y para ello, recurren a bailes, a juegos o a diversas competiciones que en unos casos son de procedencia medieval, en otros enraizan en la antigüedad clásica o simplemente reflejan algunos de los entretenimientos de la España contemporánea.

El tono de las novelas cambia, entonces, cuando el narrador se detiene en la descripción de estos episodios. Aunque algunos de los protagonistas no puedan dejar al margen su dolor, sí que son capaces de entregarse a estas diversiones, entre las que llaman particularmente la atención los.juegos, pues en buena parte de los títulos que conocemos aparecen: desde La Diana, de Montemayor a El prado de Valencia, de Gaspar Mercader, pasando por la curiosa novela de Ana Francisca Abarca de Bolea, Vigilia y octavario de San Juan Bautista, o la más conocida Galatea, 
de Miguel de Cervantes. Los juegos pueden ser tanto físicos como de ingenio (aunque en el caso de los primeros sólo participan personajes masculinos). Y ya se trate de uno u otro tipo, se acomodan perfectamente al ámbito pastoril literario. Juegos pancracios y quinquercios, juegos de cañas, de los propósitos, de las letras o de la reina se citan en varios de estos títulos, como veremos a continuación.

Su función puede ser muy distinta: constituyen un descanso para el lector en lo que a la narración de los infortunios de los pastores se refiere; del lamento se pasa a la diversión, de la introspección a la manifestación pública y colectiva de algunos sentimientos. Por otro lado, propicia la reunión de diferentes personajes, algunos de los cuales no volverán a ser citados en las páginas de estos libros, pues tan sólo han sido creados para poblar de potenciales amantes el espacio en el que se desenvuelven las diferentes acciones. Y es, además, una de las pocas ocasiones en las que los pastores compiten entre sí por obtener un premio (material y de reconocimiento), pues desde Los siete libros de la Diana, de Jorge de Montemayor, la amistad de muchos de éstos parece estar por encima de sus sentimientos; el proceso de idealización posibilitá la ausencia de la envidia o la rivalidad, que quedan al margen en la narración de sus particulares casos de amor. Recordemos a los pastores Sireno y Siralvo, ambos deseosos de ser correspondidos por Diana, aunque no por ello enfrentados; o a Elicio y Erastro en $L a$ Galatea, por citar tan sólo dos de los ejemplos más conocidos. Sin embargo, cuando juegan todo cambia, pues el juego, indudablemente, es diversión, pero su atractivo también reside en que sus participantes compitan, bien para demostrar su inteligencia, bien para dar a conocer sus dotes físicas, o para conseguir ambos propósitos. De ahí que en la mayoría de las ocasiones los vencedores sean laureados y reciban un premio acorde con sus intereses.

Por otro lado, hay que barajar la posibilidad de que estos juegos fueran trasunto de actividades frecuentes en la España del Siglo de Oro y que, en definitiva, nos hablen de algo más que de pura ficción, de algo que trasciende el espacio de lo literario al ser reflejo de algunas prácticas habituales entre un sector concreto de la sociedad española del momento, especialmente entre cortesanos. A algunos de estos juegos les acompaña la publicación de un certamen poético, enlazando entonces con el mundo de las academias literarias. 
No podemos pasar por alto el hecho de que los argumentos de estas obras, así como sus particulares características formales -libros en octavo- hicieron pensar en la posibilidad de que el público lector las asumiera como guías de comportamiento en sociedad, manuales de refinados sentimientos dirigidos especialmente a mujeres 1 . Luego, además de la sutileza del sentir de sus protagonistas, también las características de muchos de esos juegos podrían entrar en perfecta sintonía con los lectores a quienes iban dirigidos. No se cita cualquier tipo de juego. Si no recuerdo mal, en ninguno de los textos los protagonistas se entretienen con las cartas o los dados, juegos más propios de otros ámbitos bien distintos (como las ventas diseminadas por los caminos, que se convirtieron en punto de confluencia de todo tipo de personajes. Recuérdese la afición que sienten por estos entretenimientos Pedro Rincón y Diego Cortado en la venta del Molinillo o algunos de los más afamados pícaros $)^{2}$. Sería interesante recabar toda la información que sobre actividades lúdicas nos ofrece la literatura de ficción, pues el juego, que ha formado parte de la actividad del ser humano desde que el mundo es mundo, ha sido objeto de teorización y de censura en varios momentos de la historia. Para el período cme nos ocupa, basta citar los tratados de fray Pedro de Govarrubias, Remedio de jugadores (Burgos, 1519) ${ }^{3}$, de Francisco Alcocer, Tratado del juego (Salamanca, 1559) ${ }^{4}$, de Francisco de Luque Fajardo, Fiel desengaño contra la ociosidad y los juegos (Madrid, 1603) ${ }^{5}$, del padre Mariana, Tratado de los juegos públicos 6 , o de Diego del Castilio, Tratado muy útil y provechoso en reprobación de los juegos (Vallado-

1 Véase la introducción de Edwin S. Morby a La Arcadia de LOPE DE VEGA: "Pero además de proporcionar entretenimiento, estas obras sirvieron en su tiempo de manuales de sentimientos delicados, repertorios de ademanes y ejemplos del trato social exquisito" (Castalia, Madrid, 1975, p. 12). Y José F. MoNTESinos, Entre Renacimiento y Barroco: "La gran boga de la Diana se debió en parte, según parece, a las mujeres, menos exigentes sin duda que los letrados y algunos cortesanos, pero siempre agentes muy activos y eficaces en informar la sensibilidad de una época. Así parecen indicar las censuras de los moralistas, que hoy se nos antojan extremosas" (Editorial Comares, Granada, 1997, p. 98).

${ }^{2}$ Véase Jean-Pierre Étienvre, Márgenes literarios del juego. Una poética del naipe. Siglos XVI-XVHI, Támesis, London, 1990.

${ }^{3}$ BNE R/ 10268.

${ }^{4}$ BNE R/ 10903.

${ }^{5}$ Ed. M. de Riquer, RAE, Madrid, 1955, 2 ts.

${ }^{6}$ Ed. J. L. Suárez García, Universidad, Granada, 2004. 
lid, 1528) ${ }^{7}$. Bien es cierto que la mayoría de ellos establece una división entre los juegos que son perniciosos para la moral y los que no, y, en general, toman como centro de su teorización a tahúres, fulleros y tablajeros, por practicar algunos de los juegos más peligrosos, sin dar demasiados datos acerca de éstos. Pero centrémonos ahora exclusivamente en los libros de pastores y en aquellos juegos con los que estos personajes se entretienen.

\section{PANCRACIOS Y QUINQUERCIOS}

Los juegos de habilidad física más citados en este subgénero narrativo son los pancracios y los quinquercios (aunque no siempre se nombren así). Ambos, en su origen, formaban parte de los juegos olímpicos de la antigua Grecia, que fueron adaptados posteriormente en Roma. El pancracio era un deporte muy popular que constituía la tercera prueba del atletismo y que no se documenta antes del siglo $\mathrm{v}$ a.C. Combinaba muy variadas técnicas y movimientos relacionados con la lucha y el boxeo $^{8}$. Mientras que el quinquercio o pentatlo constaba de cinco pruebas: lanzamiento de disco, lanzamiento de jabalina, salto de longitud, carrera y lucha; no obstante, en ocasiones, se sustituía el lanzamiento de jabalina por el pugilato ${ }^{9}$.

La única documentación de los términos "pancracio" y "quinquercio" en un libro de pastores procede de las Tragedias de amor de Juan Arze Solórzano (Madrid, 1607). Allí los personajes acuden al templo de Apolo para festejar, con bailes y juegos, las bodas de sus compañeros Lisarda y Camilo:

Acabada la comida, que fue regalada y abundante, y alȩadas las mesas, vinieron seis çagales, y otras tantas çagalas, y cada uno a solas bailó y çapateó al son de una gaita estremadamente. Y después todos juntos empeçaron una dança vistosa y de ingenio, porque se enredavan unos entre otros, haziendo entricadas bueltas y lazos, difíciles de entender y maravillosos de mirar. A esta hora ordenó Ergasto, padre de la novia, que esto cesasse y se diesse principio a otros entretenimientos acostumbrados entre los pastores, como los juegos pancracios o quinquercios, porque no todos gustaban

${ }^{7} \mathrm{BNE} \mathrm{R} / 3202$.

8 Véase Fernando García Romero, Los juegos olimpicos y el deporte en Grecia, AUSA, Sabadell, 1992, pp. 337-344.

${ }^{9}$ Op. cit., pp. 297-309. 
de aquellos bailes. Y assí puso premios para lo que en los juegos pancracios se señalasse que allí eran luchar, correr, saltar, tirar y nadar (ff. 72r-v).

La novedad que se introduce con respecto aljuego olímpico es la incorporación de la natación como una prueba más, lo cual no sería de extrañar al tratarse de una actividad más acorde con el mundo pastoril literario. Los pastores viven casi siempre cerca de un río, de manera que cualquier tipo de entretenimiento que se desarrolle en el agua puede resultar perfectamente creíble. De hecho, en varios de los títulos que conforman el corpus aparecen otras actividades acuáticas, como las famosas naumaquias, que tanto interesaron en la antigua Roma y que también fueron del gusto de los cortesanos españoles de los siglos xvI y xvir. Al parecer, en el Palacio del Retiro había dos islitas que servían para realizar festivales acuáticos, algunos de los cuales fueron inmortalizados por pintores como el italiano Giovanni Lanfranco ${ }^{10}$. Y volviendo al ámbito de los libros de pastores, Lope de Vega realiza en la Arcadia una prolija descripción de la naumaquia organizada para celebrar la boda de Belisarda y Salicio. De manera semejante a como sucede en el último de los libros de la Diana enamorada de Gaspar Gil Polo, o en la Cintia de Aranjuez, de Gabriel de Corral.

Siguiendo también la costumbre antigua, a los mejores en cada una de las modalidades deportivas se les otorga como premio un objeto de valor de excelente calidad o ricamente adornado:

El premio para el mejor luchador, un cayado de ébano negro; para el más fuerte, un ancho cuchillo de dos cortes; para el más ligero en correr, una flauta de brasil de seis órdenes; y para el que más saltase, un zurrón de pieles de martas; para el mejor tirador de ballestas, un espejo de fino cristal; para el que más tirase la barra, una honda de cáñamo y seda (ff. 72v-95).

No volveremos a encontrar citados estos juegos pancracios o quinquercios, pero, sin embargo, no faltan textos, incluso anteriores a éste, en los que se alude a otro tipo de deportes muy similares. Así, por ejemplo, en el Desengaño de celos, de Bartolomé López de Enciso (Madrid, 1586) -uno de los muchos títulos que

${ }^{10}$ Jonathan Brown y John H. Elliot, Un palacio para elrey, Taurus, Madrid, 2003, pp. 126-127. 
alimentaron las llamas en el famoso escrutinio de la biblioteca de don Quijote- se vuelven a celebrar unos desposorios y para ello se recurre a algunas de estas pruebas:

quales pastores saltavan, quales luchavan, tiraban y corrían, y hazían otras muchas apuestas y reguzijos con que los gozosos desposados más se alegravan (f. 304r).

Bernardo de Balbuena realiza una descripción semejante en el Siglo de Oro en las selvas de Erifile (Madrid, 1608):

Y no solo esto, mas si el hado me fuere favorable, luego que el venidero día siembre su luz sobre nuestras cabezas, honrosos premios señalaré al talle de mi caudal, cortados assí para los que en cantar se aventajaren, como a los que en luchar, tirar la barra, correr o saltar por estos llanos se mostraren diestros (f. 16lv).

Y sucede algo similar al final de La constante Amarilis, de Cristóbal Suárez de Figueroa (Valencia, 1609), cuando se describen los festejos organizados con motivo de los desposorios de $\mathrm{Me}$ nandro y Amarilis, tras quienes, por cierto, parecen esconderse las figuras de doña María de Cárdenas o de la Cerda y don Juan Andrés Hurtado de Mendoza. De hecho, la obra fue escrita a instancias de este último:

Lucharon diferentes pastores animosamente, derribándose unos a otros con risa de los que miravan. $\mathrm{Al}$ fin, por más fuerte luchador tocó el premio a Arsindo, con quien ninguno pudo durar sin quedar derribado. En la carrera ocupó el primer lugar de ligero Cintio, que parecía averle para tal efeto comunicado su velocidad el planeta que le comunicó su nombre, llegando al puesto donde se avía de parar muy antes que los demás. Por pasarle delante, tropeçó Coriolano casi en sí mismo, dando tan gran caída que del segundo lugar que llevava apenas le vino a tocar el último, suceso que haziéndole quedar corrido, alegró los circunstantes. Aventajóse en tirar al blanco Olimpio, que a cincuenta pasos clavó su dardo casi en medio d'él. $Y$ dando estos y otros juegos lugar a la música, se subieron los pastores al teatro sobre que estava el assiento de los esposos, donde, acompañando Manillio su voz con lás de varios mstrumentos puesta la vista en los amantes, cantó d'esta suerte...'1.

11 C. SuÁrez DE FIGUEROA, La constante Amarilis. Prosas y versos, BNM R/1851, ff. 269-270. La única ed. moderna que se conoce se encuentra disponible en 
Todos estos ejemplos demuestran la vitalidad de estos juegos -hoy considerados deportes- dentro del marco de las novelas pastoriles; aún así, no son exclusivos de este ámbito. Por un lado, se vinculan al pastor -en sus variantes de labrador, boyero, cabrero...-, con independencia del género inaugurado por el portugués castellanizado Jorge de Montemayor. Digamos simplemente que el pastorijuega. Las palabras del anciano Nicteo en Los juegos olimpicos de Agustín de Salazar lo dejan claro: "Dexo las habilidades / pastoriles, como caça, / lucha y carrera, en que siempre / al natural acompaña / el arte..." (p. 7). Y no faltan ejemplos que lo corroboren. Véase el siguiente fragmento del primer acto de La serrana de la Vera, de Luis Vélez de Guevara:

$$
\begin{aligned}
& \text { que fuera de la presencia } \\
& \text { hermosa, tan gran valor } \\
& \text { tiene, que no hay labrador } \\
& \text { en la Vera de Plasencia } \\
& \text { que a correr no desafie, } \\
& \text { a saltar, luchar, tirar } \\
& \text { la barra, yen el lugar } \\
& \text { no hay ninguno que porfie } \\
& \text { a mostrar valor mayor }{ }^{12} \text {. }
\end{aligned}
$$

Ténganse en cuenta, asimismo, las palabras de Burgato en el Coloquio de Camila, de Lope de Rueda: "Muchos días ha, Quiral, que tú me havías de haver reconocido ventaja, assí en el arte de la lucha como en saltar, correr y tirar barra, y en todo cualquier género de buen ejercicio..."13. O las de Preteo en la Comedia Tibalda, de Perálvarez de Ayllón, cuando anima al protagonista a ejercitarse en algunos de estos:juegos como vía de escape a sus males de amor. Se subraya, así, el valor terapéutico del.juego, que conduce a la catarsis:

...Pues eres, Tibaldo, dispuesto garzón, con otros zagales devries procurar tirar a la barra, correr y saltar, que son exerçiçios que olbidan pasión;

línea dentro de la sección de textos de la revista electrónica LEMIR: http:// parnaseo.uv.es/Lemir/Textos/Amarilis/index.htm, ed. realizada por María Asunción Satorre Grau.

12 Ed. E. Rodríguez Cepeda, Cátedra, Madrid, 2000, wv. 133-141.

13 BNM R/12055. Puede consultarse una edición moderna en http:// parnaseo.uv.es/Lemir/Textos/Camila/Index.htm. 
jugar a la chueca, jugar al mojón, a veces luchar con otros pastores; no luches contino con estos dolores, pues d'ellos te viene tan gran perdiçión ${ }^{14}$.

Pero, al mismo tiempo, se asocian a otro tipo de personajes $y$, desde luego, a otros géneros literarios no exclusivamente narrativos. Véase al respecto el Oliveros de Castilla, los Conceptos espirituales de Ledesma, e incluso algunos tratados sobre el juego, como los Dias geniales o lúdricos de Rodrigo Caro. Allí, en una conversación que mantienen don Fernando y don Pedro, se da a entender que tan sólo son una rémora del pasado:

Don FERnANDo ...digo que los juegos que en aquellas fiestas se hacian eran cinco: correr, saltar, luchar, tirar y apuñearse.

Don Pedro Pero si en España quisiesen volver a hacer estos ejercicios del pentatlo o quinquercio, no me parece a mí que pudiera ser.

DON FERnANDo Es tan grande la mudanza de costumbres y tan diferentes aquellos siglos de los nuestros, que ni puede ahora ser ni aun sé si conviniera; porque la malicia de los hombres y la soberbia ha crecido demasiadamente, y cuando la humildad y sencillez cristiana debiera reducir los hombres o tenerlos reducidos a una admirable paz, conformidad y amor, parece que opuesto invidiosamente el enemigo del género humano, no cesa de sembrar discordias infundiendo en los ánimos altivez y menosprecio del prójimo, con que las cosas están en miserabilísimo estado y digno de muchas lágrimas ${ }^{15}$.

JUEGOS DE CAÑAS ${ }^{16}$

Pancracios y quinquercios son las pruebas atléticas más abundantes en la literatura pastoril, aunque no faltan casos en que

${ }^{14}$ Ed. V. Caparrós, Universidad, Valencia, 2002.

15 Ed. J. P. Etiénvre, Espasa-Calpe, Madrid, 1978, t. 1, pp. 137-138.

16 "En España en muy usado jugar las cañas, que es un género de pelea de hombres de a caballo. Éste llaman juego troyano y se entiende haberle traído a Italia Julio Ascanio. Descríbele Virgilio, lib.5, Aeneida tan por ex- 
los pastores festejan con otros juegos de habilidad física, como el de cañas, posiblemente el más citado en la literatura (tanto medieval como del Siglo de Oro ${ }^{17}$. Este conocidísimo entretenimiento, al que eran tan aficionados los caballeros andantes, los protagonistas de obras como el Guzmán de Alfarache o algunos personajes de las Guerras civiles de Granada, se considera un recuerdo de los torneos medievales, en los que la nobleza ponía en juego su destreza, habilidad y valor. Sus características y repercusiones han sido estudiadas por otros investigadores, por lo que no me detendré demasiado en su consideración. Para el caso de la novela pastoril, cito únicamente un par de ejemplos. El primero de ellos corresponde a Los pastores del Betis, de Gonzalo de Saavedra (1633). Adviértase que aparece, en compañía de los toros, como era habitual:

Procuravan la diversión de este enojoso pensamiento los pastores que habitando aquellos valles eran testigos de mi enagenada vida, ora con presurosas y porfiadas carreras, ora con valientes luchas, haziéndome juez de sus fuerças y velocidad y premiador de su ansioso trabajo, ora con enramadas y bien compuestas yeguas, fingiendo demasiados miedos, cubriendo sus animosos y sueltos cuerpos con nivelados corchos, que cubiertos de blancas pieles remedavan las africanas adargas. Después de aver fatigado algunos ligeros y valientes toros jugavan las cañas y despedían de los nerbiosos brazos algunos delgados bohordos con tanta fnerça que aunque los seguía la vista, a breve espacio se perdían della, ora batiendo los intricados manchones y espinosos çarzales de la fragosa sierra, davan caza a la que de sus confusos gritos y disonantes ladridos de los perros salía huyendo cevando en ella, qual el afilado venablo qual la tostada jara, que en venenosa yerva tocada apenas se vía del arco que salía, qual la silvadora pelota que tomando los nivelados puntos del arcabuz, aplicando el ardid, y el pedernal al rastillado azero, y las centellas del causadas a la salitrosa carga, ella encendida la despedía, dando a un tiempo fuego y con la bala muerte al animal (ff. 55-56).

tenso que no quita punto del juego de cañas. Primero desembarazan la plaza de gente, hace la entrada con sus cuadrillas distintas, acometen, dan vuelta, salen a ellos los contrarios" (CovarRubias, Tesoro de la lengua castellana o española, ed. integral e ilustrada de I. Arellano y R. Zafra, Universidad de Navarra-Iberoamericana-Vervuert, Pamplona-Madrid-Frankfurt/M., 2006).

${ }^{17}$ M. Carmen Marín Pina, "Fiestas caballerescas aragonesas en la Edad Media", Fiestas públicas en Aragón en la Edad Moderna, t. 7: Muestra de documentación histórica aragonesa (4 de diciembre de 1995-21 de enero de 1996), Diputación, Zaragoza, 1995, pp. 109-117. 
Este tipo de juegos ecuestres permitía a los participantes exhibir su habilidad con las armas así como su elegancia en el vestir. Y a este respecto hay que hablar de la obra de Gaspar Mercader, El prado de Valencia en la que realiza una descripción de este juego aludiendo a la indumentaria de los participantes, centrándose, sobre todo, en el color. No podemos pasar por alto el interés que la ciudad de Valencia mostró por las fiestas durante los siglos XVI y XVII ${ }^{18}$ :

Y Fideno lo hizo por dalles gusto, y por tener todos yeguas en que salir, escogió unijuego de cañas diziendo:

-Yo saldré en mi yegua blanca, que tendrá aquel día las uñas doradas y un jaez de monte cubierto de luneras de pavos; las cabeçadas de lo mismo, adornadas en lugar de plumas con flores naranjadas y blancas; petral de cascaveles plateados y mi persona vestida a lo morisco con marlota y capellar naranjado con infinitos coraçones de plata y otro turbante blanco y naranjadas plumas; en la blanca adarga sacaré por empresa un pavo con la rueda hecha y los pies de oro sin cosa que pueda entristecello y el mote dirá:

\author{
Por todas partes dichoso \\ vengo y voy \\ porque de Belisa soy.
}

\title{
JUEGO DE LOS PROPÓSITOS
}

De diferente índole es el denominado "juego de los propósitos". Uno de los participantes dice al oído de otro a quien tiene al lado las primeras palabras que se le ocurren. Éste añade otras con el mismo propósito o intención, y se las dice a un tercero; así sucesivamente hasta que, al final, se repite la serie entera en voz alta para que todos se enteren de lo que cada término ha suscitado en quien lo escuchaba. Cervantes, que en tantas de sus obras alude a diversos tipos de entretenimientos ${ }^{19}$, se

18 Teresa Ferrer Valls, "El duque de Lerma y la corte virreinal en Valencia: fiestas, literatura y promoción social. El Prado de Valencia, de Gaspar Mercader", Quaderns de Filologia. Estudis literaris. Homenaje a César Simón, 5 (2000), 257-271; y "La fiesta en el Siglo de Oro: en los márgenes de la ilusión teatral", Teatro y fiesta del Siglo de Oro en tierras europeas de los Austrias, SEACEX, Madrid, 2003, pp. 27-37.

19 Véase Cristina Castillo, "La paloma y otros juegos en el Persiles", Peregrinamente peregrinos. Actas del V Congreso Internacional de la Asociación de 
hace eco de este juego en La Galatea. Y, como sucede en otras ocasiones, provoca situaciones comprometidas para aquellos pastores enamorados:

-La fama de vuestra sabiduría, que cerca y lejos se estiende, discretos y gallardos pastores, es la que a estos pastores y a mí nos trae a suplicaros queráis ser jueces de una graciosa contienda que entre estos dos pastores ha nascido; y es que la fiesta pasada, Francenio y Lauso, que están presentes, se hallaron en una conversación de hermosas pastoras, entre las cuales, por pasar sin pesadumbre las horas ociosas del día, entre otros muchos juegos, ordenaron el que se llama de los propósitos. Sucedió, pues, que, llegando la vez de proponer y comenzar a uno destos pastores, quiso la suerte que la pastora que a su lado estaba y a la mano derecha tenía, fuese, según él dice, la tesorera de los secretos de su alma, y la que por más discreta y más enamorada en la opinión de todos estaba. Llegándosele, pues, al oído, le dijo: "Huyendo va la esperanza". La pastora, sin detenerse en nada, prosiguió adelante, y al decir después cada uno en público lo que al otro había dicho en secreto, hallóse que la pastora había seguido el propósito, diciendo: "Tenella con el deseo" 20 .

Muy de pasada cita este juego Lope de Vega en su Arcadia, no obstante aporta los datos suficientes para presumir que se trata del mismo:

No estaban, cuando esto pasaba entre Leriano y Galafrón, menos entretenidos Isbella, Julia, Celia, Anarda, Olimpio, Menalca y Enareto; que, después de haber cantado y entretenido algunas horas en diversos juegos -mayormente en el de los propósitos, como los que sólo pretendían declarar los suyos-, de común parecer de todos quería ya Menalca proseguir la fábula del gigante Alasto y la ninfa Crisalda, que en el bosque de pino había dejado destroncada (pp. 165-166).

Y, aunque Cristóbal de Figueroa no lo nombre con estos términos, seguramente se está refiriendo a él en La constante Amarilis. Lo interesante, en este caso, es que el juego se convierte en un ardid que usa el pastor Rosanio para poder conquistar a Ardenia:

Cervantistas (Lisboa. Fundaçao Calaouste Gulbenkian, 1-5 septiembre 2003), ed. A. Villar Lecumberri, Asociación de Cervantistas, 2004, pp. 249-268.

${ }^{20}$ Eds. F. López Estrada y M. T. López García-Berdoy, Cátedra, Madrid, 1999 , p. 374. 
la casualidad ha querido que se sentara al lado de su amada, circunstancia que aprovecha para transmitirle sus intenciones, que, en un principio, no son bien recibidas por la pastora:

un día que se sentavan en cerco muchas pastoras y zagales haziendo un juego que cada uno por su orden dixesse un secreto al oído de su vezino. Yo, que lo era de Ardenia, le dixe: "Por ti me abraso y si no me remedias, moriré". Inclinó su rostro a estas palabras, dexándole al improviso teñido de púrpura, y mostrando alteración, tuve por respuesta un silencio mudo, turbado y lleno de amenazas 21 .

Si atendemos a las palabras de Covarrubias en su Tesoro de la lengua castellana o española, el "Juego de propósitos es un entretenimien to de las doncellas". Sin embargo, los datos parecen contradecir la opinión del lexicógrafo, pues tanto en la obra de Cervantes como en la de Lope los participantes son de ambos sexos.

Con el número 376, recoge Alonso de Ledesma en sus Juegos de buenas noches a lo divino ${ }^{22}$ este mismo pasatiempo, pero esta vez en forma de romance. Con respecto al que describe Cervantes en La Galatea aparecen algunas diferencias de planteamiento, puesto que los conceptos a los que se refiere en estos versos son brevísimas pinceladas de la historia de Cristo que subrayan la importancia de la penitencia. Los participantes son los ángeles y no se pasa por alto el hecho de que Luzbel "cayera" como jugador y fuera expulsado por el arcángel san Miguel. Su lugar es ocupado por el hombre. Ledesma aprovecha la variación del concepto (de pequé a perdón) para incidir en la benevolencia de Dios.

El juego de los propósitos A LOS ÁNGELES

\section{Romance}

El juego de conceptos

a los ángeles tocó, pues por conceptos se entienden desde el mayor al menor.

${ }^{21}$ Ed. cit., pp. 139-141.

${ }^{22}$ En Romancero y Cancionero sagrados: colección de poesias cristianas, morales y divinas sacadas de las obras de los mejores ingenios españoles, por Justo de Sancha, Adas, Madrid, 1950 (BAE, 35). 
El primer concepto fue la eterna generación, donde el Padre engendra al Hijo, y dellos procede Amor. El segundo es cuando el Verbo en la Virgen encarnó, tomó la palabra Carne, y Juan le sirvió de voz. Buen concepto erró Luzbel cuando no reconoció al que es en concepto del padre, por su rey su señor. Echadle, Miguel, del juego; que en el lugar que él dejó entrará el hombre a jugar; que por eso muere Dios. Otro concepto hay humano, que es el de la confesión; el hombre lo dice al hombre, y a Dios lo dicen los dos. Llegad, penitente santa; que hoy en casa de Simón qmieren jugar un concepto, y le habéis de empezar vos.

¡Oh, qué bueno que ha salido!

Aunque el fariseo erró: Vos empezáis en pequé, y Dios acaba en perdón ${ }^{23}$.

No muy distinto de éste (tal vez pueda considerarse una variante de él) es el juego de la cinta del que Bernardo de la Vega habla en El pastor de Iberia (1591). Cinco listones de diferentes colores unen por sus cabos a los pastores, colocados de dos en dos, y ésta es la excusa para que, en secreto, digan sus propósitos y, más en concreto, para que declaren quién creen que es el pastor que las ama:

Con ellos (después de aver tratado algunos particulares del Tormes), le pidió Rosilo que inventasse algún juego donde con gusto todos se entretuviessen obligándole con su discreción y con la comunicación passada. Y él dixo que ya que le avían dado la mano, que no hallava otro (en que todos pudiessen jugar y entretenerse) 
más cómodo que el de la cinta. A todos le pareció bien porque en él podrían dezir sus cuidados y propósitos. Filardo pidió a Marfisa una liga y la pastora le dio un listón blanco (y Filardo rogó al cielo que no saliesse assí su suerte). A Jacinta pidió otra y ella dio la verde (por la esperança que tiene en sus intentos). A Silvia la pidió y diola morada (muestra del mucho que a Filardo tiene). Alcida la dio azul del color que le dan los celos del Ibero. A Nise le pidió la que faltava y diola de una red de plata y oro (en prueva de su gravedad y señorío). Y Lorino assí por venir de sobra como por su pausada melancolía dixo que él quería ver jugar porque gustaría más. Y ofreciéndole Filardo su lugar, lo escusó refieriendo lo que avía dicho. Y assí Filardo dobló las cintas y los diez cabos púsolos a propósito que tirando cada uno cupieron Silvano y Alcida, y Rosilo con Silvia, Tirseo con Nise, Marfisa con Linardo, Filardo con Jacinta. Silvano dixo al oído a Alcida mil bienes de Filardo, como aquel que lo avía menester, alabando su talle y mucha discreción. Alcida le respondió que jamás ella vio menos partes, y que por la novedad avían parecido bien sus entretenimientos. Rosilo dixo a Silvia que ninguna zagala estava tan bien empleada como ella en su pastor; esto dixo por Silvano. Y ella, tomándolo por el Ibero, respondió que aunque todos los pastores del Betis la perdonassen, que su pastor les hazía las ventajas que él los haze en luz a las estrellas. Tirseo dixo a Nise que él sabía que un pastor de aquella ribera la adorava con grandíssimos estremos, y Nise recelando con ellos el onor de su pastor le preguntó con aspereza que quién era... Algunos quedaron del juego con alegre cara y otros con semblante confuso, según cada cual tenía el alma, sobre que dixo Lorino que aquel juego se remitiesse a algunos cuentos, bailes o música que era de lo que más gustava. Y Silvano con mucha instancia pidió que se echasse otra vez la cinta y de parecer de todos se echó (f. $37 \mathrm{v})$.

También aquí se echa mano de la simbología de los colores en relación con los sentimientos de las participantes ${ }^{24}$ y, al igual que en casos anteriores, el desarrollo del juego permite que exis-

${ }^{24}$ José Manuel Pedrosa, en su artículo "La tradición del Pleito de los colores del Cancionero de Baena: de Las mil y una noches y Lope de Vega al repertorio oral hispanoamericano y sefardí" (Cancionero General, 3, 2005, 9-32), habla del simbolismo amoroso de los colores en referencia -para lo que a nosotros nos interesa- a la composición de Juan de Timoneda titulada Dechado de colores. En ésta se hace una interpretación en los siguientes términos: "Si sale la dama de color morado, denota amor", "Si sale la dama de azul, denota celos", "Si sale la dama con guarnición de plata, denota señoría", "Si sale la dama con guarnición de oro, denota majestad...". 
ta cierta tensión en las relaciones entre los pastores enamorados. Por otro lado, la existencia de los listones trae a la memoria la danza del cordón, en la que un grupo de damas en corro prendía una cinta de color atada a un árbol situado en el centro ${ }^{25}$.

\section{EL JUEGO DEL ABC}

La capacidad de invención de los pastores vuelve a ponerse en evidencia al participar en el juego de las letras, juego del abc o del abecedario, según las diversas denominaciones. Las normas aparecen descritas en El prado de Valencia, de Gaspar Mercader (Valencia, 1600). Se requiere también la presencia de varios participantes. Cada uno de ellos tendrá que elegir una letra y narrar una breve historia con unos puntos comunes: lugar del que parte, lugar al que llega, nombre del huésped que lo acoge, nombre de la comida que éste le ofrece, etc. Y todo ello con términos que empiecen con la letra elegida. Ésta es la única regla. El que pierda tendrá que pagar una prenda. Los pastores de Denia actuarán de jueces dirimiendo quién es el ganador y quién ha de cumplir penitencia. Conscientes de las connotaciones que la historia puede tener, los jueces asignan a cada pastor la letra con la que empieza el nombre de su amada y viceversa. Una vez más, el juego se transforma en un lenguaje subrepticio para el amor:

Llegaron infinitos cohetes a los cielos a dar nuevas desto a la Luna, que no osara salir aquella noche sin el roboço de sus humos, corrida de ver tantos soles en el Prado: al fin salió en ocasión que ya el pastor de Denia tenía mil alabanças dichas desta tarde: y agradeciendo a la Luna su acertada venida, empeçaron un juego entre pastores bueno, y nombrado el de la a,b,c, desta forma, que cada uno de los que jugavan avía de tomar una letra, como digamos $\mathrm{M}$. $\mathrm{Y}$ decir que salió de un lugar, o provincia, cuyo nonbre empieça por M. Llegó a otro que empieça por M. El nombre de huésped también por M. El de la huéspeda por M. Comió por principio algo que empiece por M. El medio de la comida por M. Los postres por M. Partió a otro lugar que también empieça por M. Vio en el camino un pastor, o pastora nombrado por M tan hermosa, o hermoso, como algo que se nombre por $\mathrm{M}$, y la quiere, o lo quiere como algo que también empiece por M. Este es el juego. Y el que

${ }^{25}$ Véase Ludwig Prandu, Introducción al Siglo de Oro. Cultura y costumbres del pueblo español de los siglos хи у хй, Araluce, Barcelona, 1929, p. 255. 
no acertava en todo, dava luego a los juezes una prenda; y acabado el juego la cobrava, después de cumplida la penitencia ome por el yerro se le dava. Juezes fueron los pastores de Denia, y repartieron las letras, dando a los pastores las primeras letras de los nombres de sus queridas pastoras, $y$ a las pastoras bellas las letras primeras de los nombres de sus galanes. Dióle a Fideno por letra B a Belisa por letra $\mathrm{F}$ a Cardenio, A. Y a Arcinda, C. A Dinarda, O. Y a Olimpo, D; a Nisida, L. Y a Lisardo, N (pp. 131-133).

Merece la pena comentar, aunque sea someramente, dos de los casos en que los pastores tienen que pagar una prenda. El primero de ellos por cuanto el fallo de Fideno está en haber confundido dos letras b y v, que ya en la época y en el lugar en el que aparece la obra se escriben y se pronuncian de manera diferente. Lo cual constituye una prueba de que por entonces, y al menos en la zona, se daba la diferenciación:

Mandaron los juezes a Fideno que diesse principio a este juego: y luego él a vista de infinitas atapadas y arreboçados que los avían cercado, empeçó diciendo: "Señores, yo salí vna vez de Buñol, y llegué a Burgos. El huésped era Bernardo; la huéspeda, Beatriz. Diéronme Berros, Bonitalo, y Berengenas dulces. Partíme a Buitrago, topé con Belisa, tan hermosa como Venus, y quiérola como Bien".

Todas las bocas de los oyentes fueron ecos de lo que dixo Fideno, diciendo bien a vna boz. Sólo el pastor de Denia le dixo: "Venga una prenda Fideno, que has errado el juego, diciendo que Belisa es tan hermosa como Venus, y el nombre de Venus, ni escrito, ni pronunciado no empieça por B" (pp. 133-134).

Y el segundo, por su carácter jocoso, ya que Olimpo, que ha elegido la letra $\mathrm{D}$, es penalizado por decir que quiere a su amada Diana "como al dinero" (p. 141), rompiendo con ello toda la pasión que rodea al juego y suscitando la risa y la sonrisa en los participantes y, en última instancia, en el lector.

Y assí passó el juego adelante Olimpo, diziendo. Yo salí una vez de Dinamarca, y entré en Dacia a posar en casa de Domingo, y de Dorotea; comí, Dátiles, y de un Delfín, y duraznos; y passando a Denia tope con Dinarda hermosa como Diana, quiérola como al dinero. El pastor de Denia reprehendio muchíssimo la comparación que hizo Olimpo del amor de su dama al amor del dinero, como no decente por cierto al parecer de todos; y assí con general consentimiento fue penado por ello, y huvo de dar en prendas un rabel de pinauete, y euano... (p. 141). 
Los últimos juegos que estamos analizando precisan del concurso de varios participantes y tienen vinculación con el amor. Estos dos elementos son idóneos para que se desarrollen en ámbitos sociales. Esta idea se puede apoyar en la incorporación en Le chansonnier espagnol d'Herberay des Essarts (XVe siècle), de una composición en verso que reproduce el citado juego de las letras ${ }^{26}$.

[Juego trobado].

\section{A}

En Ávila por la A posará el rey en persona.

Alfonso se llamará el huéspet y ella Antona. Y serán las condiçiones de la su bolatería anadones y ansarones y combrá su Señoría d'un gentil asno aquel día.

Avellanas le darán por fruta luego de mano. El comer le guisarán con almendro y avellano.

Dirá la su cançión "Amor yo nunca pensé" cantada con gentil son. El refrán por buena fe es este que vos diré:

"Amansar deve su saña quien por sí mesmo s'engaña"

\section{$\mathrm{B}$}

A Burgos irá por B el rey a cas de Veltrán. La huéspeda nombraré; Brianda 1[a] llamarán. Dar l'an en plato de barro estas dos aves primero, un gran buitre y un buarro y los pechos d'un bezerro puesto en un taiadero.
Beuras si le plaze puede su mayordomo traer, y con buxo maguer que fiede l'apareien el comer. "Buena pascua y ventura" a tres vozes cantarán por quitarle de tristura y después le contarán con que se ría este refrán: "Bien canta Marta quando está farta".

C

Váyase el rey d'Aragón par la C a Çaragoza el huéspet será Catón ella Costança y la moça. Él combrá de dos capones que los asse Álvaro vieio Y muerto con dos falcones Y le traerán un gran coneio guisado con salmoreio.

Denle por fruta cogombros de los de agora dos anyos y traigan sobre los hombros mucha lenya de castaños. "Con qualquier pena que siento" le cante Iohan de la Fuente, porque pierda el pensamiento de moteiar a su gente con este refrán siguiente: "Cedaçillo nuevo tres días en estaca" [...Así hasta completar todas las letras del abecedario] (pp. 188-196).

${ }^{26}$ Ed. C. V. Aubrun, Féret et Fils, Bordeaux, 1951, CC. 
Las únicas variantes con respecto a aquél se refieren, por un lado, a la forma (en este caso en verso); a cada una de las letras se le dedican dos estrofas de nueve versos cada una más un villancico final (ABABCDCDD ABAB CDCDD EE). Y, por otro lado, al contenido último de la narración, pues ahora se incorpora una canción y un refrán, en lugar del pastor al que encuentran por el camino y al que comparan en hermosura con algo que empieza por la misma letra. Hay que precisar, además, que, en el juego trovado del Chansonnier, algunos de los personajes en él citados formaban parte de la corte de Leonor de Navarra, tal y como indica Charles Aubrun en su edición, lo que corroboraría la idea de que se trata de un juego que refleja una realidad social concreta ${ }^{27}$.

En el citado auto de Mira de Amescua, Nacimiento de Christo, nuestro bien..., unos pastores recurren para entretenerse a este mismo juego de las letras. Los términos comunes serán el lugar al que se viaja, el huésped que lo hospeda, así como la comida y el postre con que le agasaja. Por las palabras de algunos de los personajes, parece ser un juego bastante conocido, puesto que Mendrusco, al que le han ofrecido la letra G, se niega a jugar con esta letra -no sin gracia-, por lo poco-dice- que se puede comer con ella:

\begin{tabular}{|c|c|}
\hline Celio & $\begin{array}{l}\text { No, } \\
\text { que es viejo. }\end{array}$ \\
\hline FLO & Pues sea el soldado. \\
\hline Cis & $\begin{array}{l}\text { Ya aquese habemos jugad } \\
\text { mucho. }\end{array}$ \\
\hline $\mathrm{BE}$ & Pues uno sé yo. \\
\hline & Si es t \\
\hline & . Fa l \\
\hline
\end{tabular}

27 “ "Nous nous bornerons à suggérer que le chansonnier d'Herberay fut compilé par un signeur de la Cour de Leonor de Navarre et de Foix» (p. xiv). Ainsi, le «jeu trouvé» sous forme d'abécédaire se situe à la Cour de Navarre, entre 1450 et 1462. Comme il n'offre d'in térêt, avec sa longue énumération de noms et ses plaisanteries pour autrui cryptiques, que pour les familiers de la maison royale, nous sommes amené à penser que tout le Chansonnier fut recueilli par un personnage de cette Cour, ou bien pour lui-même ou bien à l'adresse de quelque autre qui, la connaissant non moins bien, pouvait mettre un visage sur les noms et broder des souvenirs sur les incidents rapportés dans le poèmee. Voici donc que s'oriente notre enquête. C'est d'abord la Cour littéraire navarro-aragonaise que nous nous proposons de délimiter et d'étudier" (p. xxxvi). 
BelaRdo

Cintio

Celio

BELARDO

Celio

MENDRusco

Sí.

Antiyerjugar le vi.

Yitodos los que aquí estamos. $¿ A n s i ́$ ? Pues no le advirtamos. Yo tomo la $\mathrm{C}$.

¿qué me cabrá?

Yia mí

Belardo Lo que quieras.

Yo tomo la A.

FLORINDO

Yo la D.

Silvano Yo la $\mathrm{F}$, por la $\mathrm{Fe}$.

Silvia Yo la E.

MENDRUSCo ¡Oh! Estas quimeras yo sé que las pagaré.

Cintio Yo tomo la B.

BELARDO

Y tú, Frío, ¿qué letra quieres tomar?

Silvano De su flemaza me río.

Mendrusco Pues déjamelo pensar.

Belardo ¿Cuál quieres?

Mendrusco

La etcétera, tío.

BELARDo Toma otra; acaba ya, que esta no es letra.

Mendrusco ¿No es?

Alto, pues tomo la $\mathrm{K}$.

Belardo A quien tan cansado es ¿por qué le metéis acá? Toma la G, bobarrón.

Mendrusco La G, pues ¿qué comeré fuera de guijas, guijón, guijarros? No puede ser; no está bien puesto en razón.

La L es bien que celebre, porque comeré lenguados, lechón, lomos de adobados, leche, lampujas y liebre, lampreas y otros pescados.

Belardo Comienzo, pues tengo la A.

Fui a Antioquía y allá posé en cas de Albano, un hombre de buena fama y renombre que rico y bien puesto está. Dióme a comer avellanas, un ánade bien eoeido, muy relleno y bien manido; 
Cintio

por postre, almendras tempranas.

Pues yo llegué a Barcelona,

posé en cas de Baltasar

mi amigo, grave persona,

el cual me dio de cenar

berros de charcos, borona

y vitela a lo italiano

y vaca en un salpicón...28.

Entre los distintos juegos que practican Los pastores de Belén. Prosas y versos divinos, de Lope de Vega, obra escrita en 1612, catorce años después de La Arcadia (pp. 572-573), uno de ellos es una versión del juego del abe. Se trata, obviamente, de un texto de pastores espiritual, por lo que también este juego tiene una función que va más allá del puro entretenimiento. Las letras no son las de abecedario, sino las que componen el nombre de "María Virgen". Once letras para los once pastores que se dirigen a Jerusalén a ver a la madre de Dios y que optan por este juego como modo de alabarla:

-El juego de las letras solíamos hacer a otros propósitos, dijo Elifila, me parece a mí que será el mejor de todos para el nuestro.

-Quien le supiere le declare, respondió Fabio.

-Ninguno pienso que le ignora en estos valles, dijo Ergasto entonces; pero para que mejor se entienda es de esta suerte. Las letras de este nombre, María Virgen, como veis, son once; éstas se han de repartir entre nosotros, y si sobrare alguno, tenga paciencia y sea juez.

-Antes parece que veníamos desde las cabañas a esto, dijo Niseida, porque entretanto que hablabas he contado los que somos y es el mismo número que las letras.

-Cada uno está obligado, prosiguió Ergasto, a decir, en tocándole su letra un atributo a la Virgen, y llamar la letra que le pareciere para que el dueño de ella haga lo mismo en decir el suyo y elegir otra; pero porque tenga más dificultad, será bien añadirle que la comparen a alguna cosa, aunque todas estarán tan lejos de parecerla, y digan juntamente algún oficio que haga por nosotros, con advertimiento que cualquier cosa de éstas ha de empezar por la letra que se tocare...

Y Ergasto prosiguió así:

${ }^{28}$ A. M. Martín Contreras, Los autos de navidad de Antonio Mira de Amescua. Edición crítica y filológica con estudio introductorio, tesis doctoral, Granada, 2005, vv. $901-951$. 
-Por mi letra M digo que María es Madre de Dios, que en esto bien sé que no diréis cosa con que podáis igualarme, y digo que parece la mayor maravilla que Dios ha hecho, y que es su oficio ser un maestro perfectísimo de todas las virtudes. Pero dime, A primera: ¿quién es María?

-María, dijo Aminadab, es arco del cielo, parece a la Virgen Abisac, y es su oficio animar los afligidos. Pero dime, letra V, ¿quién es María?... ${ }^{29}$.

\section{OTros Juegos}

Para ir concluyendo este análisis de los distintos juegos pastoriles, me referiré a tres más, pues se podría hablar de otros, como el de la pájara pinta, del que me ocuparé con más detenimiento en otro trabajo.

Con el nombre de juego de la reina se hace alusión en el libro segundo de El pastor de Iberia a un pasatiempo consistente en otorgar poder a una pastora para decidir sobre los demás. Este artificio sirve a la elegida para manejar los hilos de las relaciones amorosas de sus compañeros, y aunque en el nombre sea una mujer la que aparece, lo cierto es que el protagonismo lo asumen también los pastores, supuestos "cortesanos" de esta fingida "reina", pues el tema es, una vez más, el amor:

A cabo de un buen rato, pidieron al de Iberia que inventasse algún juego en que todos se entretuviessen. Y Filardo dixo que se jugasse el de la Reina, que en las riberas del Tajo á sido y es más celebrado, y que en las del Betis no parecería mal. Preguntáronle la manera d'él. Respondió, que a una de las pastoras avían de hazer reina, y que como tal la avían de obedecer, y que si es discreta y de buen gusto, mandaría cosas graciosas. A todos agradó el juego, y de su parecer eligieron por rema a (la que lo era de todas) Marfisa... y la discreta Marfisa que avía menester poco para representar una reina, poniendo el rostro grave con palabras graves dixo: "Esto es de mi opinión, que para que el juego sea de más gusto, como reina, mando que todos juréis que lo que por mí fuere mandado, lo haréis vosotras pastoras sin melindres de mugeres, y vosotros, pastores, sin dificultad ni estremos... Va de juego. Mando que Jacinta diga amores a Filardo y le pida celos de que quiere a otra zagala", y luego Jacinta dixo sin hallar dificultad en lo mandado... Marfisa dixo, baste, y casi arrepentida de lo que avía mandado,

${ }^{29}$ Ed. de A. Carreño, PPU, Barcelona, 1991, pp. 572-573. 
y recibiendo alguna manera de enojo dixo: "Tirseo como que as sabidio lo que passa, rine a Jacinta, y amenaza a Filardo diziéndole que si quiere a tu pastora y olvida a la suya, que as de hazer gravíssima vengaça" (f. 59r-v).

La ficción creada alrededor de este juego, así como la supremacía de uno de los participantes sobre los demás enlaza con el tradicional juego del obispillo (herencia de las fiestas saturnales) y con otras variantes en que se corona a un niño como rey con la autoridad suficiente para mandar durante un período de tiempo determinado. Es el caso del rey de la faba, o del rey de los cerdos, de los que habla por extenso Julio Caro Baroja ${ }^{30}$.

Ya hemos podido comprobar cómo Lope de Vega en su vasta obra incluye varios juegos, populares o no. En el libro II de Los pastores de Belén incorpora uno que llama la atención por su carácter alegórico, acorde con la configuración de la obra, puesto que se trata de un libro de pastores espiritual. Lo importante es que se alecciona a partir de un juego y son los propios protagonistas los que se convierten en depositarios de esa fe que se intenta transmitir, ya que cada uno, de acuerdo con las leyes del juego, asume una virtud o acción heroica y, en función de ésta, expone cuáles son las causas que generan la locura en el mundo:

-Paréceme -dijo Alfesibeo en acabando Pireno su canción-, pues es al mismo propósito, que jugásedes aquel juego de los locos con que otras veces en iguales ocasiones soléis entreteneros.

-Yo no lo sé -dijo Finarda-, y algunos pastores que están aquí dicen lo mismo.

-Las leyes son -replicó el Rústico (un labrador de aquellos campos, a quien todos llamaban con este título desde sus tiernos años) - tomar cada uno el nombre de una virtud o acción heroica $y$, en siendo preguntado, decir tres cosas en que puede parecerle que consiste la locura del mundo.

-Moral es esse juego y no poco entretenido -dixo Finarda-, pero ¿quién le sabrá jugar de improviso con la gracia y presteza necessaria?

-Al que errare -dixo el Rústico-, tomarémosle una prenda para dalle después el castigo que nos pareciere a propósito.

-Yo he hecho concepto de vuestra intención -replicó Finarda-, y ayudaré por mi parte, aunque sé bien que me pongo a peligro de incurrir en la pena por momentos.

${ }^{30}$ Véase, especialmente, la tercera parte de El Camaval. Análisis históricocultural, Taurus, Madrid, 1986. 
-¿Qué nombres tomas? -prosiguió Llorente, que éste era el legítimo del Rústico-.

-La Fama seré yo -respondió Finarda-.

A quien siguiendo los demás por su orden, Elifila tomó la Liberalidad, Damón la Filosofía, Lesbia la Discreción... y comenzó ansí:

-Dime, Filosofía, ¿en qué consiste la locura del mundo?

-En el fingir los hombres que saben -dixo Damón-, y en no saber que no saben, y en sustentar que saben; pero dime, Silencio, ¿en qué consiste?

-En hablar sin tiempo -dixo Ergasto-, y en no conocer el tiempo, y en dexar passar el tiempo; mas dime, Discreción, ¿en qué consiste?... (pp. 224-225).

En esta misma obra se citan otros juegos como el del soldado, según el cual al Niño Dios se le considera un soldado que se encuentra desnudo, por lo que los pastores proponen vestirlo con ropas de diferentes colores, todos ellos con alguna simbología de su magestad:

En tanto que los pastores suspendían las selvas, las fuentes y los montes con su apacible canto, Feniso y Pireno habían determinado que a contemplación del santísimo Niño, desnudo sobre las pajas de aquel dichoso pesebre, se entretuviesen los pastores en el juego del soldado, que les pareció muy a propósito de su desnudez y frío y de la valentía con que venía de la guerra, si no del reino de la paz a la guerra del mundo, si bien no había en su reino faltado guerra, pues entre sus ángeles fue tan sangrienta en el principio de su creación y vencida por los méritos suyos, y en virtud de la sangre que tantos años después había de derramar por los hombres. No fue difícil de concertar el juego, por la noticia que de él tenían todos; y así fueron eligiendo las colores con grande regocijo, los que como más diestros se ofrecieron y más amor y devoción mostraron.

-Yo visto a este Soldado valeroso, que yace desnudo en aquel pesebre, dijo Aminadab, de color encarnado, que pienso que es la que ahora le ha venido más a propósito...

-Yo visto a este Peregrino del cielo y soldado de la tierra, dijo el pastor [Pireno], de blanco, que significa entre nosotros castidad, y en Él la divinidad, que con el velo encarnado viene cubierta.

-Yıyo, prosiguió Dositea, le visto de pardo, que significa trabajo, pues El tiene dicho que desde su juventud se quiere ajercitar en ellos, como se ve tan claro, pues desde el instante que nace padece...

Cuando Aminadab y Elifila respondieron: "Encarnado" y 
"Morado", ya los pastores les acusaban juntos, y ellos rendidos al arbitrio del juez, se prevenían, humildes, al castigo. Condenólos Llorente a que cantasen (Libro III).

Alude a él Abarca de Bolea en la Vigilia y octavario, aunque sin dar mucha más información:

Gran risa causó el donoso chiste de Marica bajo de aquel emporio de pizarras, dándole todos la enhorabuena de su buen gusto. Y sentándose en lo menos escabroso de aquel pináculo montaraz, fraguaron el juego de vestir al soldado, que, aun en cosa de entretenimiento, quisieron ejercitar obra de virtud (pp. 255-256).

Y una vez más, Alonso de Ledesma nos brinda una versión divinizada de este juego en redondillas. En este caso, además de vestir a Dios, hay que vestir también al hombre, soldado que ha quedado desnudo tras la guerra emprendida contra el pecado:

El juego de vestir al soldado.

A las obras de virtud.

\section{Redondillas}

De la guerra del pecado desnudo el hombre salió y pues en cueros quedó vistamos a este soldado. La naturaleza humana vista a su Dios lo primero que Él dará, pues es Cordero, para vestirnos su lana. Y vós rico descuidado que veis al pobre mendigo sin calor y sin abrigo, ¿qué mandáis para el soldado? Si por lo que el mundo diga obras de virtud no hazéis, hazed vós lo que devéis y dad al mundo una higa. Vestid al pobre por Dios, que si lo venís a dar por vuestro particular, una higa para vós (impreso, f. 6r-v). 


\section{REFLEXIONES ÚLTIMAS}

Son varios, por tanto, los distintos juegos que nos brinda la literatura pastoril. Salvo pancracios, quinquercios y cañas, el resto -como hemos visto- son juegos que no dependen de las condiciones físicas de los participantes, sino de su habilidad mental para responder a las preguntas que se les plantean o a las narraciones que se les proponen y que se van enlazando con otras planteadas a sus compañeros. De más está decir el gusto que se sentía en la época por la retahilas y los encadenamientos de palabras, como muy bien muestra la literatura popular.

Es necesario insistir en que todos ellos son juegos conocidos, al menos así lo dan a entender los autores de las obras en las que aparecen: los pancracios y quinquercios son "otros entretenimientos acostumbrados entre los pastores", según las Tragedias de amor. El de las letras es "bueno y nombrado" (Elpastor de Valencia) y de él dice Ergasto en Los pastores de Belén: "Ninguno pienso que le ignora en estos valles". Y, por último, el de la reina "en las riberas del Tajo á sido y es más celebrado, y que en las del Betis no parecería mal", según El pastor de Iberia.

Estos juegos podían constituir un atractivo más para el lector cortesano, que no sólo podía aprender modos de comportamiento en sociedad en los libros de pastores, sino también podía ver reflejadas algunas de las formas de entretenimiento más habituales. Y, además, en el caso de las obras espirituales, con una importante carga doctrinal. De manera que los libros de pastores nos aportan más información de la que en principio se podría pensar.

Estas novelas, en muchos casos escritas en clave, con referencia cifrada hacia unos personajes reales aunque disfrazados por medio del lenguaje ideal propio de los libros de pastores, nos aportan, con estas alusiones o descripciones, una nueva visión de algunos aspectos de la sociedad contemporánea, si no en forma de juego que se pudiera practicar entonces, sí, al menos, como muestra del interés por este tipo de entretenimientos del pasado. 
